\title{
EDUCAÇÃO PROFISSIONAL INTEGRADA NA REDE PÚBLICA ESTADỦAL DA BAHIA: A EXPERIÊNCIA DO CENTRO TERRITORIAL DA REGIÃO METROPOLITANA DE SALVADOR/BA ${ }^{12}$
}

\author{
Aline de Oliveira Costa Santos ${ }^{3}$ \\ Avelar Luiz Bastos Mutim ${ }^{4}$
}

\begin{abstract}
Resumo
O artigo apresenta resultados de uma pesquisa que discutiu a política de educação profissional (EP) no Brasil e teve por objetivo apresentar os desafios da construção da proposta de Educação Profissional Integrada (EPI) na Rede Pública Estadual da Bahia. Foi realizada a análise da literatura pertinente e de documentos que estruturam a Rede Pública de Educação Profissional da Bahia, de 2007 a 2014, além da pesquisa de campo no Centro Territorial de Educação Profissional da Região Metropolitana de Salvador - CETEP-RMS onde se ouviu gestores, discentes e docentes. Concluiu-se que a proposta de Educação Profissional Integrada se constitui como desafio de natureza epistemológica, histórica, política e pedagógica.
\end{abstract}

Palavras-chave: Trabalho e Educação. Educação Profissional. Ensino Médio Integrado.

\section{Resumen}

El artículo presenta resultados de una investigación que discutió la política de educación profesional (EP) en Brasil y tuvo por objetivo presentar los desafíos de la construcción de la propuesta de Educação Profissional Integrada (EPI) en la Red Pública Estadual de Bahía. Se realizó el análisis de la literatura pertinente y de documentos que estructuran la Red Pública de Educación Profesional de Bahía, de 2007 a 2014, además de la investigación de campo en el Centro Territorial de Educação Profissional da Região Metropolitana de Salvador - CETEP- RMS donde se oyó gestores, discentes y docentes. Se concluyó que la propuesta de Educação Profissional Integrada se constituye como desafío de naturaleza epistemológica, histórica, política y pedagógica.

Palabras clave: trabajo y educación; Educación Profesional; Escuela Secundaria Integrada.

\footnotetext{
${ }_{1}^{1}$ DOI: https://doi.org/10.22409/tn.16i30.p10325

$2 \mathrm{O}$ artigo apresenta parte dos resultados da dissertação de mestrado "Educação Profissional Integrada na Rede Pública Estadual da Bahia: Desafios da Construção de uma proposta de educação para a classe trabalhadora", apresentada em 2014 ao Programa de Pós-Graduação em Educação e Contemporaneidade da Universidade Estadual da Bahia e foi apresentado originalmente na 38ª Reunião da Associação Nacional de Pós-Graduação e Pesquisa em Educação - ANPED.

2 Pedagoga e doutoranda do Programa de Pós-Graduação em Educação e Contemporaneidade da Universidade Estadual da Bahia. Email: olliveiracosta@gmail.com

${ }_{3}^{3}$ Professor Titular da Universidade do Estado da Bahia. Email: mutimavelar@gmail.com
} 


\section{Introdução}

O artigo visa apresentar parte dos resultados de uma pesquisa que teve como finalidade analisar os desafios da construção de uma política de educação integral para a classe trabalhadora. Neste texto, buscamos alcançar dois objetivos básicos. O primeiro é apresentar os elementos teóricos e históricos da análise empreendida na pesquisa, que nos fez compreender que a proposta de educação profissional integrada ao ensino médio é um desafio epistemológico, histórico e político. O segundo objetivo é apresentar a experiência do Estado da Bahia no processo de reestruturação e expansão da oferta pública de educação profissional e a análise dessa política a partir da escuta dos atores que a constroem cotidianamente: gestores, professores e estudantes.

Em 2007, o Governo do Estado da Bahia criou a Superintendência de Educação Profissional - Suprof e consequentemente definiu a Educação Profissional como uma política pública prioritária de Estado. A partir de 2008, o governo expandiu de forma exponencial a oferta de cursos de educação profissional para todo estado com o apoio técnico e financeiro do Programa Brasil Profissionalizado, iniciativa do governo federal. Em 2014, a rede estadual de educação profissional da Bahia já era a segunda maior ofertante dessa modalidade de ensino no país, atrás somente do estado de São Paulo, segundo o censo escolar INEP/MEC.

Diante do exposto, a questão principal que moveu a pesquisa foi: Quais os desafios da Educação Profissional Integrada (EPI) na Rede Pública Estadual da Bahia, enquanto proposta de formação integral para a classe trabalhadora? De acordo com Ramos (2012) os programas oriundos da política de integração estão em construção e em disputa:

\footnotetext{
A análise fecunda sobre eles é uma necessidade histórica e política, e o método de análise das mesmas precisa buscar compreender o que é o Brasil hoje, os segmentos que disputam o projeto de país e as marcas históricas que o fazem como são (RAMOS, 2012, p.44).
}

A revisão de literatura sobre a problemática em jogo envolveu: a) a discussão sobre a ontologia do trabalho (MARX 1996; LUKÁCS 1978; FRIGOTTO 2005; SOUSA JÚNIOR 2009); b) a compreensão dos conceitos de trabalho como 
princípio educativo, politecnia, educação omnilateral e educação tecnológica (GRAMSCI 2000; NOSELLA 2004; SAVIANI 2007; KUENZER 2009) e c) uma análise sobre a historicidade da educação profissional no Brasil, seu "controvertido percurso" nos últimos anos e a proposta de educação profissional integrada (MANFREDI, 2002; FRIGOTTO; CIAVATTA E RAMOS, 2005; OLIVEIRA, 2012; MOURA, 2012).

Para análise da execução da política implementada na Bahia foi realizada a análise de documentos oficiais e pesquisa de campo no CETEP-RMS, que incluiu visitas, observações, coleta de dados, entrevistas com a equipe gestora e aplicação de questionários com 7 docentes e 71 estudantes dos Cursos de Educação Profissional Integrada: Técnico em Segurança do Trabalho; Técnico em Controle Ambiental e Técnico em Eletromecânica.

$\mathrm{O}$ artigo encontra-se organizado em duas partes, a primeira apresenta os fundamentos teóricos que subsidiaram a pesquisa. E a segunda apresenta a Rede Pública Estadual de Educação Profissional da Bahia, sua estrutura física, administrativa e pedagógica e a análise da materialização da política a partir dos atores envolvidos.

\section{Desafios da proposta de educação profissional integrada ao ensino médio}

A proposta de uma educação integral para a classe trabalhadora, em última análise visa restituir o vínculo entre trabalho e educação que foram historicamente cortados e "remendados" aos modos dos processos de trabalho, privando o homem de compreender a sua própria existência (FRIGOTTO, 2005; SAVIANI, 2007). Para a tradição marxista a chave para romper com essa lógica está na própria natureza do trabalho, no que tange à sua dimensão emancipadora. Sousa Junior (2010) afirma que:

No contexto das relações estranhadas, o processo longo de formação do homem encontraria possibilidade de superar as relações vigentes, erigindo uma nova ordem social, na qual seja possível viabilizar o livre desenvolvimento das potencialidades humanas. Em decorrência disso, o problema fundamental da educação, no entendimento de Marx, vai localizar-se essencialmente no processo de educação do proletariado, por ser esse o agente que sofre mais intensamente a opressão do capital e por ser ele, consequentemente, o portador das condições mais 
favoráveis para conduzir o processo de superação das relações estranhadas (SOUSA JUNIOR, 2010, p.25-26).

A consciência dessa dupla face do trabalho: alienadora e emancipadora nutriu e ainda nutre a defesa de uma educação integral para a classe trabalhadora. As formulações de Marx, Engels e Gramsci se constituíram em referências conceituais, epistemológicas e metodológicas do campo Trabalho e Educação. Nota-se, nesse campo, certa convergência de posições no que tange à proposta de uma educação que tome o trabalho como referência, como fundamento e/ou como princípio educativo (MOURA, LIMA FILHO e SILVA, 2012, p.10). Por todo exposto, entendemos que a proposta da integração se apresenta primeiro como um desafio epistemológico.

A história da educação profissional no Brasil reflete a luta permanente entre duas alternativas: a implementação do assistencialismo, da aprendizagem mecânica versus a proposta da introdução dos fundamentos da técnica, das tecnologias, e do preparo intelectual (CIAVATTA, 2005, p.87). A retrospectiva desse processo mostra que a integração também se constitui como um desafio histórico. Para efeito desse trabalho, destacamos as ações do Governo de Luís Inácio Lula da Silva (2002-2010) no que tange a educação profissional, momento em que Oliveira (2012) chega a afirmar que "[...] a educação profissional assumiu uma importância jamais vista na história da educação brasileira" (p.84).

Para Ramos (2012) o Governo Lula, dispôs-se a reconstituir a política pública para a educação profissional, tendo duas ações iniciais como marco: a primeira foi a revogação do decreto 2.208/97, o que restabeleceu a possibilidade de integração curricular dos ensinos médio e técnico como propõe a Lei de Diretrizes e Bases da Educação - LDB 9394/96, e a segunda tratou do redirecionamento dos recursos do Programa de Expansão da Educação Profissional - Proep para o setor público, que se destinavam majoritariamente a iniciativa privada. Para a autora:

A revogação do decreto 2.208/97, realizada pelo decreto $5.154 / 2004$, buscou, fundamentalmente, restabelecer os princípios norteadores de uma política de educação profissional articulada com a educação básica, tanto como um direito das pessoas quanto como uma necessidade do país [...] (RAMOS, 2012. p.38).

O Decreto 5.154 de 23 de julho de 2004 substituiu o decreto anterior e foi o principal documento a regular a educação profissional no Brasil até 2008. Embora 
posteriormente outros documentos (Decretos, Leis e Diretrizes) tenham sido fixados com a função de estabelecer normas para o campo e/ou alterar o próprio, pode-se afirmar que o referido decreto se constituiu como um marco fundamental para as transformações ocorridas na educação profissional de 2004 até os dias atuais.

$\mathrm{Na}$ época da aprovação do referido decreto, alguns autores o acusavam de "reiterar" os princípios do decreto $2.208 / 97$, principalmente no que diz respeito à flexibilidade e fragmentação da oferta dos cursos de EP (RAMOS, FRIGOTTO e CIAVATTA, 2005; RODRIGUES, 2004). Outros, porém, ressaltavam que o mesmo seria de fundamental importância para o início de um processo de transformação. Moura (2012) afirmava que:

De qualquer maneira a possibilidade de integração entre ensino médio e educação profissional, constante no decreto 5.154/2004, representa uma possibilidade de avanço na direção de construir um ensino médio igualitário para todos, pois, apesar de não confundir com a politecnia, fundamenta-se em seus princípios e exigência de uma sociedade na qual a elevada desigualdade econômica que obriga grande parte dos filhos das classes populares a buscar, bem antes dos 18 anos de idade, a inserção no mundo do trabalho visando complementar a renda familiar (MOURA, 2012, p.58).

No segundo mandato do governo Lula (2007-2010), duas metas foram colocadas visando estabelecer os rumos do ensino médio e da educação profissional no país. A primeira diz respeito à continuidade da reestruturação do ensino médio. $E$ a segunda vincula-se à ampliação do ensino técnico e tecnológico nesse mesmo período. Tais metas foram materializadas em forma de ação por meio do Programa Brasil Profissionalizado, instituído pelo Decreto no 6.302, de 12 de dezembro de 2007, com a finalidade principal de estimular o ensino médio integrado à educação profissional (BRASIL, 2007).

O Programa previa o apoio técnico e financeiro da União para estruturação de redes estaduais e municipais de Educação Profissional. Com relação à sua execução, as dificuldades foram grandes nas redes estaduais, pois a ideia base é a de que o governo federal financiasse a infraestrutura física, principalmente a construção e a adequação de prédios, os equipamentos dos laboratórios e acervo bibliográfico. E os estados teriam responsabilidades com algumas contrapartidas, 
inclusive com a garantia de formação do quadro de professores, o que não aconteceu (MOURA, 2012).

Na primeira gestão do Governo de Dilma Rousseff (2011-2014), percebemos mudanças nas diretrizes da educação profissional, principalmente pelos esforços empreendidos na oferta dos Cursos de Formação Inicial - FIC do Programa Nacional de Acesso ao Ensino Técnico e Emprego - PRONATEC e o consequente arrefecimento dos investimentos na proposta de educação profissional integrada. A análise da correlação de forças que disputa a educação profissional mostrou que a proposta de integração é também um desafio político.

\section{A rede pública estadual de educação profissional da Bahia: desafio pedagógico}

Com o apoio da política nacional de integração, o Governo do Estado da Bahia na gestão Jaques Wagner - PT (2007-2014) se dispôs a construir a rede estadual de educação profissional do ponto de vista físico (escolas, equipamentos) e pedagógico (concepção, atualização curricular e formação de professores). Para isso, uma das primeiras ações do Governo foi a criação da Superintendência de Educação Profissional - Suprof e o lançamento do Plano Estadual de Desenvolvimento da Educação Profissional, no qual o Governo assume a educação profissional como política pública de Estado nos seguintes termos:

a) Vinculada ao Desenvolvimento Sócio-Econômico-Ambiental; b) Desenvolvida nos Territórios de Identidade; c) Para atender aos alunos e egressos da Escola Pública, elevando a sua escolaridade; d) Contribuindo para a inserção cidadã no Mundo do Trabalho; e) Formando Cidadãos, Trabalhadores, Sujeitos de Direitos em sua Diversidade; f) Fundamentada na Pedagogia do Trabalho (BAHIA, 2008).

Segundo informações oficiais da própria Superintendência, o Estado aproveitou estruturas desocupadas existentes na rede estadual de ensino e recursos federais do Programa Brasil Profissionalizado para adequar e modernizar várias unidades escolares, o que incluiu reforma e ampliação, instalação de laboratórios e montagem do acervo bibliográfico (BAHIA, 2011). Assim, em um curto espaço de tempo o atendimento alcançou 123 municípios baianos, como mostra a figura abaixo: 
Figura 1 - Distribuição Espacial da Rede de Educação Profissional - 2006 e 2014.1

Rede Estadual de Educação Profissional da Bahia
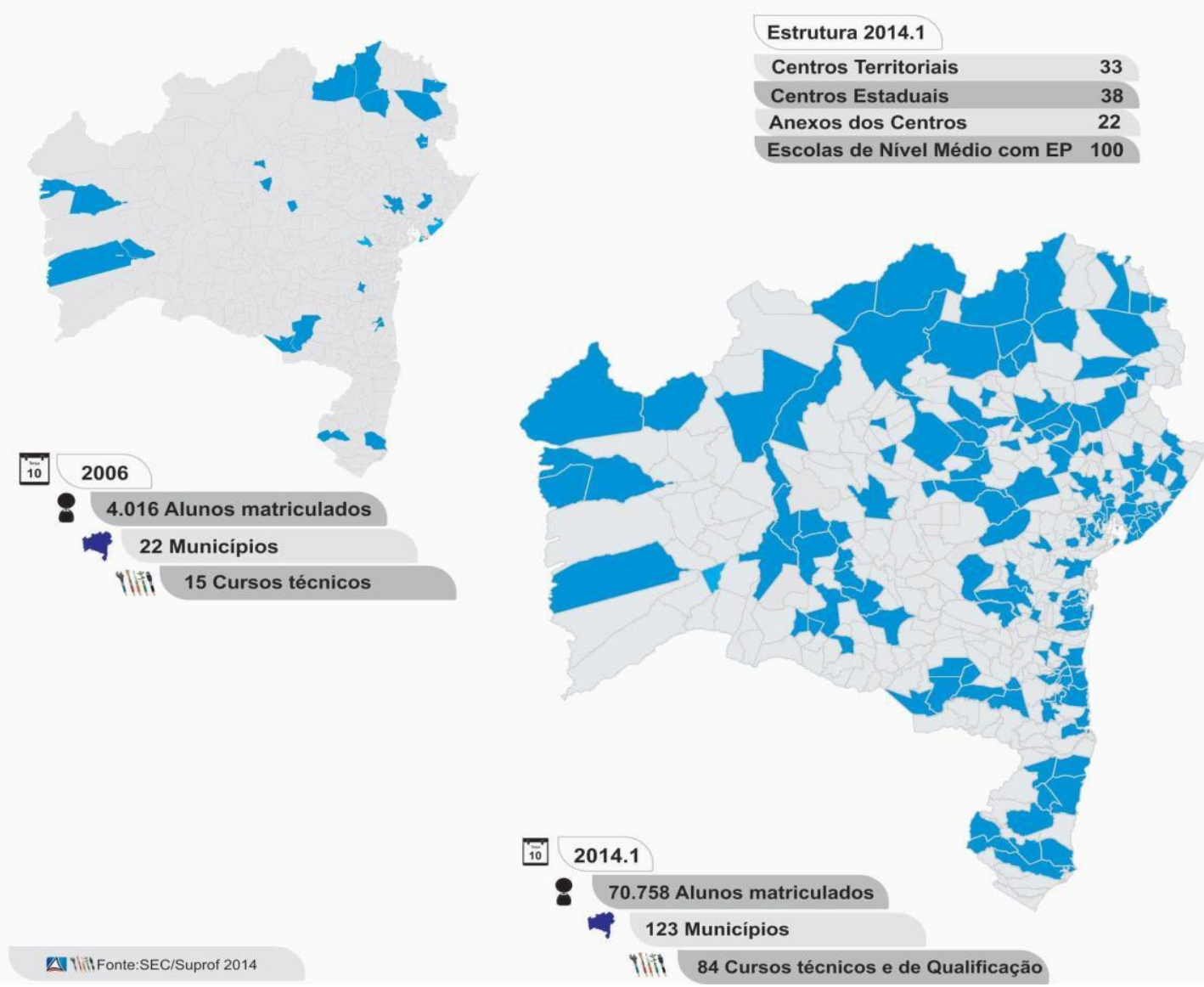

Fonte: SEC/Suprof

Outro importante marco na estruturação da política foi a instituição dos Centros Estaduais de Educação Profissional - CEEP e dos Centros Territoriais de Educação Profissional - CETEP. A diferenciação dessas instituições não é apenas de terminologia, tem a ver com a abrangência das mesmas. O CETEP visa atender às demandas consideradas relevantes da região ou Territórios de Identidade, onde se encontra situado, podendo ofertar cursos de Eixos Tecnológicos diversos. $\mathrm{O}$ CEEP se caracteriza pela especialidade em uma área ou Eixo Tecnológico.

Uma diretriz importante para o processo de gestão democrática dos Centros foi a instituição do Conselho Escolar, como órgão colegiado de caráter deliberativo, com o objetivo de ampliar e garantir a participação da comunidade, visando à qualidade dos cursos ofertados e o fortalecimento do projeto político-pedagógico 
desenvolvido. Os Conselhos devem ser compostos por segmentos da comunidade escolar e da comunidade local e entidades representativas. Todavia, Silva (2013) afirma que:

No tocante ao exercício da gestão democrática nos Centros de Educação Profissional da Bahia é possível observar que isto ainda não se concretizou plenamente em virtude da ampliação de representatividade nos conselhos escolares e da dificuldade destes em se reunirem (SILVA, 2013, p. 79-80).

Além dos Centros, a Rede Estadual de EP é também composta por unidades escolares de ensino médio que ofertam cursos de educação profissional e por escolas conveniadas ${ }^{4}$. Conforme informações divulgadas pela Suprof, em 2013 havia: 32 Centros Territoriais; 34 Centros Estaduais; 89 unidades compartilhadas e 2 escolas conveniadas. As formas de articulação ofertadas pela Rede de Educação Profissional estão expostas no quadro a seguir:

Quadro 1 - Formas de Articulação da Rede Estadual de Educação Profissional da Bahia.

\begin{tabular}{|c|c|c|}
\hline Curso & Nível & Duração \\
\hline Educação Profissional Integrada & Técnico & 4 anos \\
\hline $\begin{array}{l}\text { Educação Profissional Técnica de Nível Médio } \\
\text { Concomitante }\end{array}$ & Técnico & $\begin{array}{l}\text { Variável (conforme o } \\
\text { curso }\end{array}$ \\
\hline $\begin{array}{l}\text { Educação Profissional Técnica de Nível Médio } \\
\text { Subsequente (Prosub); }\end{array}$ & Técnico & 2 anos \\
\hline PROEJA Médio & Técnico & 2 anos e meio \\
\hline $\begin{array}{l}\text { PROEJA Fundamental, em Regime de } \\
\text { alternância }\end{array}$ & Técnico & * \\
\hline PROJOVEM & Básico & 6 meses \\
\hline PRONATEC - FIT & Básico & 4 meses (em média) \\
\hline PRONATEC - TEC & Técnico & 1 ano \\
\hline
\end{tabular}

Fonte: Suprof. Elaboração própria.

\footnotetext{
${ }^{4}$ Escolas conveniadas são instituições privadas que mantém convênios com o Estado para a oferta de educação profissional. De acordo com informações de funcionários da SEC, as escolas conveniadas de educação profissional funcionaram até dezembro de 2014. Depois desta data, as escolas passaram a funcionar como as demais, com a responsabilidade exclusiva do Estado.
} 
A oferta dos cursos ocorreu de acordo com as necessidades por qualificação e formação profissional nos Territórios de Identidade, apontadas por diferentes atores sociais e no Plano Plurianual Participativo - PPA do Governo. O preenchimento das vagas para os cursos técnicos subsequentes é feito por meio de sorteio eletrônico, com isso a Suprof pretendeu enfrentar a questão da meritocracia. Os demais cursos atendem à forma clássica de preenchimento de vagas ofertadas pela rede estadual de ensino, ou seja, reserva de vagas para os alunos da rede e ordem de chegada para os novos.

A expansão da rede pública de educação profissional da Bahia entre 2007 e 2014 foi bastante significativa. Trata-se de um crescimento de $1.661 \%$ de acordo conforme informações da Suprof. As matrículas de cursos de educação profissional alcançavam a marca de 4.016 em 2006 e saltou para 70.754 em 2014, marca que fez a Bahia alcançar, já em 2013, o posto de segunda maior rede estadual de educação profissional do país.

Dois aspectos são relevantes nesta expansão, o primeiro diz respeito a capilaridade da oferta, ou seja, a sua interiorização para o alcance de todos os territórios baianos, e o segundo envolve a distribuição das matrículas por formas de articulação, informação contida no gráfico a seguir:

Gráfico 1 - Matrículas na Rede Estadual de Educação Profissional por Forma de Articulação

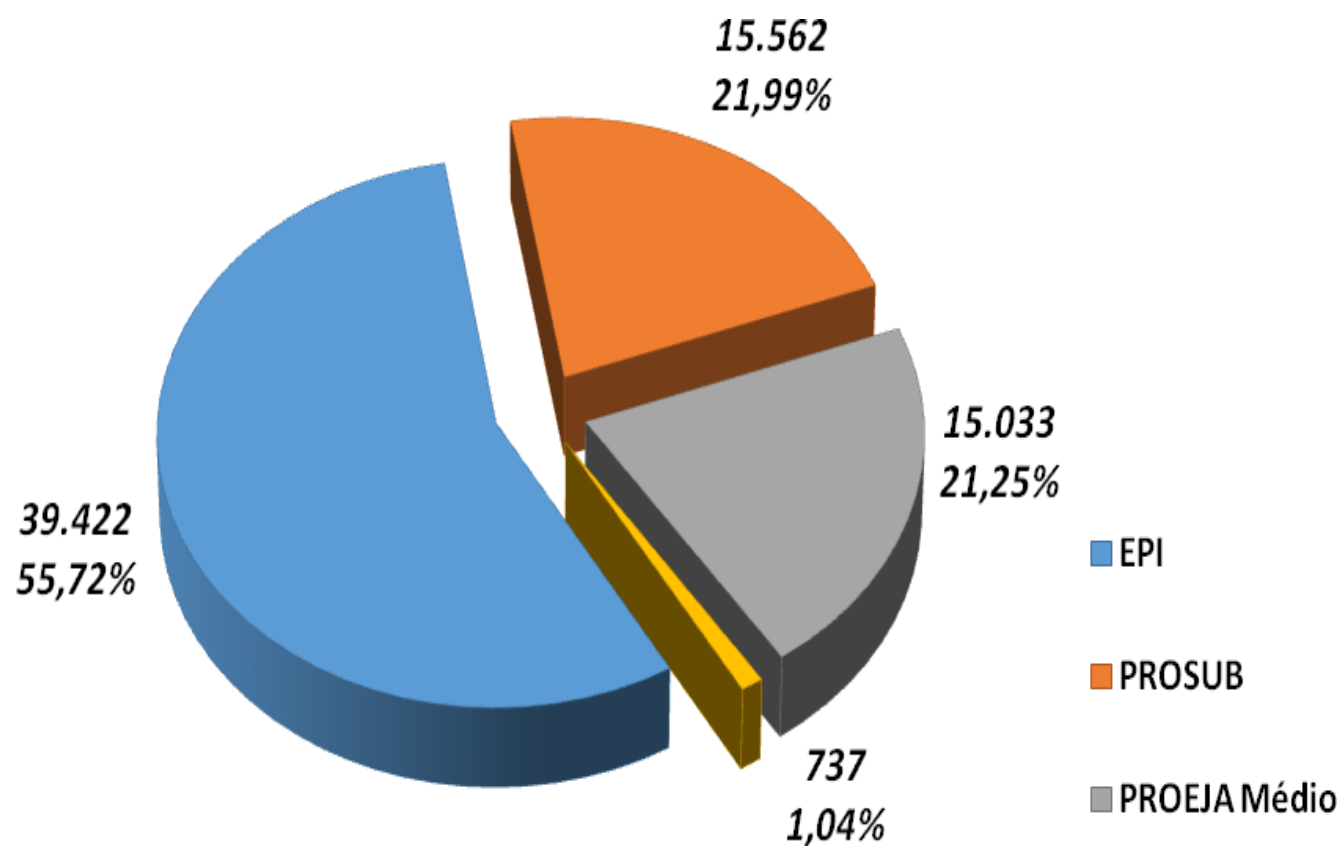

Fonte: Secretaria de Educação do Estado da Bahia/ Superintendência de Educação Profissional 
Os cursos da Educação Profissional Integrada e do PROEJA respondem pela maior parte das matrículas, o que significa o cumprimento do disposto no Programa Brasil Profissionalizado, que determina atenção prioritária à forma de articulação integrada. Com relação a oferta dos cursos do PRONATEC, a Superintendência informou que em 2014 foram 7.759 matrículas nos Cursos FIC e 3.595 nos Cursos TEC, totalizando 11.354 matrículas ofertadas em parecerias com entidades do Sistema $S$ e dos Institutos Federais (BAHIA, 2014).

Três princípios norteiam a política de EP na Bahia: 1) Formação Integral; 2) Trabalho como Princípio Educativo e 3) Intervenção Social como Princípio Pedagógico. Pela adoção de tais princípios percebemos, do ponto de vista da intencionalidade, o compromisso com a formação integral da classe trabalhadora. Contudo, da forma como foram expostos, notamos a presença de elementos da Pedagogia das Competências, propagada na década de 1990. O texto oficial diz o seguinte:

\begin{abstract}
A Educação Profissional está articulada às diferentes formas de educação, trabalho, ciência e tecnologia. Está voltada, também, ao permanente desenvolvimento da capacidade dos estudantes de adaptar-se, com criatividade e inovação, às condições das ocupações e às exigências posteriores de aperfeiçoamento e de especialização profissional (BAHIA, 2013, grifo nosso).
\end{abstract}

A ideia de uma educação voltada "ao permanente desenvolvimento da capacidade dos estudantes em adaptar-se, com criatividade e inovação, às condições das ocupações" remete às noções de flexibilidade e formação por competências, as quais são opostas a noção de formação integral. Nesse sentido, entendemos que há uma tendência de associação direta da formação profissional com o mercado de trabalho e com o empreendedorismo, o que marca um posicionamento recorrente nas políticas de EP.

Contudo, ressalta-se que o Governo do Estado ofereceu três Cursos de Especialização aos docentes da Rede, fundamentados na Pedagogia HistóricoCrítica. Os cursos foram: Metodologia de Ensino para Educação Profissional; Gestão da Educação Profissional e Trabalho Educação e Desenvolvimento para Gestão em Educação Profissional (UFRB). Sendo que 1.500 docentes concluíram os cursos. 
A matriz curricular dos cursos de Educação Profissional Integrada é formada por componentes curriculares de três áreas: (1) Base Nacional Comum (BNC); (2) Formação Técnica Específica (FTE) e (3) Formação Técnica Geral (FTG). Os cursos têm duração de 4 anos, com carga horária total de 4.680 horas, incluindo a carga horária de estágio. Mesmo diante de alguns limites de contradições entendemos que a proposta curricular apresentada pode possibilitar uma formação integral. Para analisar a materialização da proposta adentramos no cotidiano do Centro Territorial de Educação Profissional da Região Metropolitana de Salvador.

\section{A experiência do Centro Territorial da Região Metropolitana de Salvador - CETEP-RMS}

O CETEP-RMS é uma instituição da rede pública estadual de ensino que se dedica exclusivamente a oferta da educação profissional em suas diversas formas de articulação. O Centro está localizado em Camaçari, um dos treze municípios que compõe a Região Metropolitana de Salvador, também denominada de Território de Identidade 26.

Em 2014, encontravam-se matriculados no Centro 956 estudantes distribuídos nos três turnos, $20 \%$ nos Cursos de Educação Profissional Integrada, $55 \%$ nos Cursos Técnicos Subsequente, e os demais, em Cursos do PROEJA Médio (13\%) e do PRONATEC (12\%). Situação que denota certo descolamento do que propôs o Programa Brasil Profissionalizado, no que concerne à priorização da oferta de matrículas da Educação Profissional Integrada. Embora se tenha verificado que no conjunto do estado, a oferta da EPI supera as demais modalidades.

O CETEP-RMS ocupa uma área situada no centro de Camaçari e está instalado em um prédio de dois andares e dois pavimentos, com 10 salas de aulas, cantina, espaços de convivência e 10 laboratórios instalados conforme indicação do Catálogo Nacional dos Cursos Técnicos - CNCT. A infraestrutura do Centro é avaliada pela comunidade escolar como boa ou ótima, mas os estudantes reclamam da falta de uma quadra de esportes e da pouca utilização dos laboratórios para aulas práticas.

Os professores reconheceram que utilizam pouco os laboratórios e alegam que isso ocorre pela ausência de um técnico de laboratório na instituição para dar 
suporte e pelo pouco tempo de aula que dificulta a realização de aulas práticas. Entendemos que a ausência de uma quadra de esportes e a pouca utilização dos laboratórios compromete bastante a proposta de uma educação integral.

\section{Precarização dos profissionais do Centro}

O quadro dos servidores do CETEP-RMS estava formado por 49 profissionais, dos quais 20 eram de professores, sendo: 07 efetivos, 04 contratados

pelo Regime Especial de Direito Administrativo - REDA e 09 por Prestação de

Serviço Temporário - PST. Entre os demais servidores, a maioria (24) era contratada por tempo determinado ou por empresas terceirizadas, com exceção da diretora, dos vice-diretores e de uma secretária que fazia parte do pessoal efetivo.

Segundo a equipe gestora, a rotatividade dos profissionais que atuam na instituição é alta. A remuneração e as condições de trabalho oferecidas aos profissionais contratados são apontadas pelos professores como motivos para 0 não preenchimento das vagas existentes, como apontou um dos professores participante da pesquisa.

"Enquanto um professor efetivo com regime de $20 \mathrm{~h}$ deve dar $13 \mathrm{~h}$ em sala de aula, dispondo das outras horas para planejamento/correção de trabalhos, o contratado através do PST tem que assumir até $18 \mathrm{~h}$ em sala de aula. Isso para ganhar menos que a metade de um professor efetivo". (PROFESSOR CETEPRMS).

As formas precarizadas de contratação de professores e funcionários é um problema da rede estadual de educação em geral, e que atinge a educação profissional de forma particular pela necessidade de contratação de professores especializados para as disciplinas técnicas. Sabemos que o déficit de professores para a educação profissional e tecnológica é uma realidade em todo Brasil, como apontou Oliveira (2005). Mas, esperávamos que o Governo da Bahia cumprisse com o compromisso assumido de tornar a EP como política de Estado com a realização de concursos para contratação de funcionários e professores efetivos da rede.

\section{Desconhecimento da proposta}


O desconhecimento dos estudantes sobre a proposta da Educação Profissional Integrada foi apontado pela equipe gestora e pelos professores como um dos entraves para o sucesso da proposta. Dos 71 estudantes que participaram da pesquisa, 46\% afirmaram desconhecerem o curso antes da matrícula. Tal desconhecimento leva os estudantes a questionarem a necessidade dos 4 anos de duração do curso e das disciplinas da Base Nacional Comum na matriz curricular.

"Os alunos questionam muito a presença das disciplinas da Base Nacional Comum no currículo. Eles questionam: 'Por que Sociologia?' Eles querem um curso técnico direcionado. Queixamse porque tem Intervenção Social e Pesquisa" (VICE-DIRETORA PEDAGÓGICA CETEP-RMS).

Verificamos que o desconhecimento tem gerado problemas sérios, uma vez que provoca um descompromisso por parte dos estudantes em relação ao curso. Por outro lado, alguns professores assumiram que não gostam de dar aulas nas turmas de EPI, pelo fato dos estudantes serem mais jovens, segundo eles "inexperientes e mais indisciplinados" em relação aos dos cursos subsequente e Proeja. A nosso ver, estes comentários também refletem certo desconhecimento dos professores em relação a proposta, pois diziam: "a minha matemática é aquela do segundo grau"; "falta neles (estudantes da EPI) uma postura profissional". O que reflete uma visão estritamente profissionalizante da proposta. No CETEP-RMS dois professores e um membro da equipe gestora concluíram os cursos de especialização em metodologia da EP, ofertado pelo Estado, o que proporcionalmente é muito pouco.

\section{Articulação entre trabalho, ciência e cultura}

O compromisso da EPI é com a formação do estudante em todas as suas dimensões. Nesse sentido, é necessário que aconteça a articulação entre arte, cultura, tecnologia e trabalho na formação. Essa articulação, muitas vezes é o ponto nevrálgico dessa proposta. A matriz curricular desenvolvida prevê os Estudos Interdisciplinares com carga horária semanal como forma de promover essa integração. 
A frequência em que se desenvolvem atividades ou projetos interdisciplinares nos Cursos de EPI foi uma questão direcionada aos estudantes. Dos quais $90 \%$ afirmaram que raramente foram realizados trabalhos ou projetos interdisciplinares durante o curso. Sabemos que atividades interdisciplinares não garantem a integração, entretanto tal proposta requer uma intersecção de saberes e conhecimentos e, em geral, atividades de natureza interdisciplinar são as que mais se aproximam dos princípios da integração, uma vez que requerem práticas contextualizadas e articuladas com as questões sociais mais amplas da sociedade em geral e da comunidade em que a escola está inserida.

Aos professores também foram perguntados sobre a frequência com que realiza atividades interdisciplinares e as respostas dadas pelos 07 professores ratificam o que disseram os alunos. Apenas uma professora admitiu que realiza atividades interdisciplinares 04 vezes ao ano, outros 05 afirmaram que fazem semestralmente um trabalho dessa natureza, e um professor admitiu não fazê-lo.

Em meio às dificuldades, no Centro pôde se observar, em alguns momentos, a materialização da proposta de educação integral e dos princípios que embasam a política de educação profissional da Bahia. Momentos que se concretizaram também pelo esforço coletivo de professores e estudantes que sentiram a necessidade de significar pela contextualização as questões que impactam o lugar onde vivem e se relacionam.

Em uma das atividades a professora de Filosofia, Ética e Direito do Trabalho juntamente com o Professor de Língua Portuguesa propuseram que os estudantes organizassem um seminário sobre o livro "O Cortiço" de Aloísio de Azevedo, observando as relações de trabalho estabelecidas no romance e fazendo um paralelo com as relações de trabalho contemporâneas. Essa atividade reafirma a proposta da formação integrada, que de acordo com Ramos (2014):

[...] não somente possibilita o acesso a conhecimentos científicos, mas também promove a reflexão crítica sobre os padrões culturais que se constituem normas de conduta de um grupo social, assim como a apropriação de referências e tendências estéticas que se manifestam em tempos e espaços históricos, os quais expressam concepções, problemas, crises e potenciais de uma sociedade, que se vê traduzida e/ou questionada nas manifestações e obras artísticas (RAMOS, 2014, p.90). 
Os estudantes, em equipes, apresentaram seminários nos quais foi possível observar a integração no mais completo sentido do termo: integração de um conteúdo clássico da literatura brasileira com o um conteúdo da ética do trabalho; análise de uma realidade do século XIX em paralelo com a análise das condições sociais atuais dos trabalhadores no Município de Camaçari; integração de saberes profissionais, saberes científicos e saberes culturais. E principalmente, uma análise crítica sobre a realidade social do Brasil nos dias atuais.

Outra atividade observada foi a Feira Tecnológica, evento que acontece anualmente no Centro. A atividade funciona como uma espécie de preparação para as Feiras Estaduais de Educação Profissional. Nessas feiras, os estudantes apresentam resultados de pesquisa realizada, sob a orientação dos professores. Foi possível observar nas pesquisas apresentadas um viés intervencionista, voltado para as questões da comunidade e um amplo envolvimento dos estudantes. Entretanto percebemos que a articulação entre trabalho, ciência e cultura, um dos pilares principais da Educação Profissional Integrada, é algo vivenciado em atividades pontuais no Centro, quando na verdade deveria ser o eixo condutor das ações.

\section{Defesa pela continuidade da política}

São constantes os protestos e reivindicações da comunidade do CETEPRMS em relação a proposta da Educação Profissional Integrada ao Ensino Médio. Gestores, professores e estudantes apontam falhas e equívocos, mas também defendem a continuidade da política por considerar importante e necessária para formação dos jovens. A comunidade em geral faz referência aos investimentos, a proposta dos cursos e a necessidade de resolução dos problemas apontados. Alguns estudantes registraram apreciações a respeito da experiência:

"A estrutura do CETEP-RMS para uma instituição técnica é diferenciada, é muito boa, na verdade é ótima. Precisamos de mais estímulo dos docentes, é o dever deles nos passar as informações da realidade em sala de aula e nos fazer profissionais" (ESTUDANTE, EPI, SEGURANÇA DO TRABALHO 4ํANO);

"Este curso, inicialmente seria uma proposta de estudo ideal. Ao longo desses quatro anos, muitas experiências boas foram vividas, porém com baixa frequência (constância), sendo abafados pelos 
problemas e precariedades que a instituição apresenta e mascara" (ESTUDANTE, EPI, CONTROLE AMBIENTAL 4ํANO).

A grande maioria dos estudantes que participaram da pesquisa afirma que pretende prosseguir os estudos no ensino superior ou cursar outro curso técnico. A

preocupação com o futuro profissional era algo bastante perceptível entre os estudantes. Sentimento que os faziam cobrar dos professores a contextualização dos conteúdos, algo que os aproximassem mais das questões por eles vivenciadas.

Gestores e professores do CETEP-RMS também se manifestaram a favor da continuidade da política, mas apontaram a necessidade da realização de concurso público para provimento dos cargos de professores para a educação profissional no Estado. Entendemos que mesmo com infraestrutura adequada e proposta curricular consoante com o princípio da educação integral, foi possível verificar também a existência de mais um desafio para a efetivação da proposta de integração: o desafio pedagógico. Para Lima, 2011:

\begin{abstract}
A resolução de nenhum destes desafios prescinde de um ator destinado a ser protagonista, mas que tem assumido ultimamente "papéis baratos": os trabalhadores, que devem assumir a cena, o roteiro e a direção na construção de uma nova política de educação profissional no Brasil (LIMA, 2011, p.18).
\end{abstract}

O caminho para que a classe trabalhadora assuma um papel preponderante na construção da política pública de EP é a garantia do direito a uma educação pública, gratuita, de qualidade e socialmente referenciada, que se resume na defesa de uma educação integral.

\title{
Considerações finais
}

Entendemos que proposta da educação profissional integrada se constitui como uma tentativa de construção um "novo" ensino médio, anterior a atual Reforma imposta inicialmente pela Medida Provisória n.746/2016 e regulamentada pela Lei n. 13.415/2017. Reforma que desconhece todo esforço empreendido nacionalmente, de forma democrática, para construção de caminhos para o ensino médio e, de forma subliminar anuncia a descontinuidade da política de integração, fere frontalmente o princípio da educação básica e legitima uma educação dualista (FRIGOTTO, 2016; FARIA FILHO, 2016). 
A experiência do CETEP-RMS mostrou que na prática a proposta da educação profissional integrada enfrenta alguns entraves, como a questão dos vínculos precários de contratação dos profissionais do Centro, o desconhecimento da proposta por parte de estudantes e professores, e ainda, as dificuldades para articulação entre trabalho, ciência, cultura e tecnologia. Entretanto, mostrou também a materialização de experiências que abrem "espaços de esperança" e nos fazem acreditar na integração enquanto mediadora da tão sonhada formação integral para classe trabalhadora.

A compreensão da EPI como desafios: epistemológico, histórico, político e pedagógico torna-se imprescindível para o reconhecimento das dimensões dos embates que deverão ser enfrentados para sua concretização. O momento atual aponta para a importância de resistirmos na defesa de um ensino médio público, gratuito e que garanta uma formação completa e/ou integral para classe trabalhadora, visto que historicamente esta é a mais prejudicada com as Reformas Educacionais.

\section{Referências}

BAHIA. Decreto o1 11.355/2008. Diário Oficial do Estado da Bahia, em 04 de dezembro de 2008.

. Educação Profissional da Bahia. Trabalho, Educação e Desenvolvimento. Legislação Básica 2010-2011.

. A Rede Pública de Educação Profissional do Estado da Bahia. Material audiovisual disponibilizado pela Suprof. 2014.

BRASIL. Lei n. 9.394, de 20 de dezembro de 1996. Estabelece as diretrizes e bases da educação nacional. Diário Oficial da União, Brasília, DF, 23 dez. 1996.

. Decreto n. 2.208. Regulamenta o $\S 2^{\circ}$ do art. 36 e os artigos 39 a 42 da Lei 394, de 20 de dezembro de 1996, que estabelece as diretrizes e bases da educação nacional. 17 de abril de 1997.

Decreto n. 5.154. Regulamenta o $\S 2^{\circ}$ do art. 36 e os artigos 39 a 41 da Lei n. 9.394, de 20 de dezembro de 1996, que estabelece as diretrizes e bases da educação nacional. 23 de julho de 2004

. Decreto n. 6.302. Institui o Programa Brasil Profissionalizado. 12 de dezembro de 2007.

. Medida Provisória n. 746, de 2016. Institui a Reformulação Ensino Médio. 
Médio.

. Lei n. 13.415, de 16 de fevereiro de 2017. Lei da Reforma do Ensino

CIAVATTA. Maria. A formação integrada: a escola e o trabalho como lugares de memória e de identidade. In: Gaudêncio Frigotto, Maria Ciavatta, Marise Ramos (orgs.), Ensino Médio Integrado: Concepções e contradições. São Paulo: Cortez, 2005.

CIAVATTA, Maria; RAMOS, Marise. A "era das diretrizes": a disputa pelo projeto de educação dos mais pobres. Rev. Bras. Educ. [online]. 2012, vol.17, n.49, pp. 11 37.

FARIA FILHO, Luciano Mendes de. A MP do Ensino Médio - Ponte para o passado. Publicado em 22/09/2016. Disponível em https://blogdopensar.wordpress.com/2016/09/22/a-mp-do-ensino-medio-pontepara-o-passado/. Acesso em 28/09/2016.

FRIGOTTO, Gaudêncio. Reforma de ensino médio do (des)governo de turno: decreta-se uma escola para os ricos e outra para os pobres. Publicado em 22/09/2016. Disponível em: http://www.anped.org.br/news/reforma-de-ensinomedio-do-des-governo-de-turno-decreta-se-uma-escola-para-os-ricos-e-outra.

Acesso em 28/09/2016.

. O enfoque da dialética materialista histórica na pesquisa educacional. In: Ivani Fazenda (org.). Metodologia da Pesquisa Educacional. São Paulo. Cortez. 1989.

A dupla face do trabalho: criação e destruição da vida. In: Gaudêncio Frigotto e Maria Ciavatta (Orgs.). A experiência do trabalho e a educação básica. Rio de Janeiro: DP\&A, $2^{\underline{a}} e d .2005$.

FRIGOTTO, Gaudêncio; CIAVATTA, Maria; RAMOS, Marise (Orgs.). Ensino médio integrado: concepções e contradições. São Paulo: Cortez, 2005.

GRAMSCI, Antônio. Caderno 23. Americanismo e Fordismo. In: . Cadernos do Cárcere. Trad. de Carlos Nelson Coutinho. Rio de Janeiro: Civilização Brasileira. 2000.

KUENZER, Acácia Zeneida. O trabalho como princípio educativo. In: Dicionário da Educação Profissional em Saúde. 2009. Disponível em http://www.epsjv.fiocruz.br/dicionario/verbetes/trapriedu.html. Acesso em 24/03/2014.

LIMA, Antonio Almerico Biondi. Educação profissional para quê? Construindo a formação dos trabalhadores para além do falso consenso. Revista Trabalho, Educação e Políticas Públicas. Instituto Integrar. Confederação Nacional dos Metalúrgicos da CUT. Ano XV, n. 7, novembro de 2011. 
LUKÁCS. As Bases Ontológicas do Pensamento e da Atividade do Homem. (1978). Tradução de Carlos Nelson Coutinho. Disponível em: http://moviments.net/espaimarx/docs/818f4654ed39a1c147d1e51a00ffb4cb.pdf. Acesso em 03/03/2014.

MANFREDI, S. Educação profissional no Brasil. São Paulo: Cortez, 2002.

MARX, Karl. O Capital. Crítica da economia política. Rio de Janeiro. Editora Nova Cultura. 1996.

MOURA, Dante Henrique. Políticas Públicas para a Educação Profissional Técnica de Nível Médio nos anos de 1990 e 2000: Limites e Possibilidades. In: Ramon de Oliveira (Org.). Jovens, Ensino Médio e Educação profissional: políticas públicas em debate. Campinas - SP: Papirus, 2012.

MOURA, Dante Henrique; LIMA FILHO, Domingos Leite; SILVA. Monica Ribeiro da. Politecnia e formação integrada: confrontos conceituais, projetos políticos e contradições históricas da educação brasileira. Trabalho encomendado pelo GT 09. 35를 Reunião Anual da ANPEd. Porto de Galinhas-PE, 2012.

NOSELLA, Paolo. A escola de Gramsci. Porto Alegre: Artes Médicas, 3. ed, 2004.

OLIVEIRA, Maria Rita N.S. A Formação de Professores para o Ensino Técnico. Projeto de Pesquisa. Brasília, CNPq, 2005.

OLIVEIRA. Ramon. Por uma educação profissional democrática e emancipatória. In: Jovens, Ensino Médio e educação profissional: Políticas públicas em debate. Campinas, SP: Papirus, 2012.

RAMOS, M.; FRIGOTTO, G.; CIAVATTA, M. A gênese do decreto n. 5.154/2004: um debate no contexto controverso da democracia. Revista Trabalho Necessário, Niterói, n. 3, 2005.

RAMOS. Marise Nogueira. A educação tecnológica como política de estado. In: Jovens ensino médio e educação profissional: Políticas públicas em debate. Campinas, SP: Papirus, 2012.

. História e política da educação profissional [recurso Eletrônico] Curitiba: Instituto Federal do Paraná, 2014. - (Coleção formação pedagógica; v. 5).

SANTOS, Aline de Oliveira Costa. Educação Profissional Integrada na Rede Pública Estadual da Bahia: Desafios da Construção de uma proposta de educação para a classe trabalhadora. 2015. 162f. Dissertação (Mestrado em Educação e Contemporaneidade). Universidade Estadual da Bahia, Salvador.

RODRIGUES, José. Quarenta anos adiante: breves anotações a respeito do novo decreto de educação profissional. Niterói: UFF, 03/08/2004.

SAVIANI, Demerval. Trabalho e educação: fundamentos ontológicos e históricos. Revista Brasileira de Educação, v. 12, n. 34, jan.-abr. 2007. 
SILVA, Rosany Kátia Vilasboas Moreira. Conselho escolar nos centros de educação profissional da Bahia: representatividade e desafios de atuação. 2013. 81f. Dissertação (Mestrado em Educação). Universidade do Estado da Bahia, Salvador.

SOUSA JUNIOR. Justino de. Marx e a crítica da educação: da expansão liberal democrática à crise regressivo-destrutiva do capital. Aparecida, SP: Ideias \& Letras, 2010.

O programa Marxiano de educação e o fundamento da práxis.

$\overline{T r a b . E d u c . S a u ́ d e, ~ R i o ~ d e ~ J a n e i r o, v .7, s u p l e m e n t o, p .51-66,2009 . ~}$

Recebido em: 23 de março de 2018. Aprovado em: 10 de maio de 2018. Publicado em: 21 de novembro de 2018. 